\title{
Design-oriented modeling of circular FRP-wrapped concrete columns after sustained axial compression*
}

\author{
Hui LIU ${ }^{1}$, Ming-hua $\mathrm{HE}^{\dagger \ddagger 1,2}$, Jia GUO ${ }^{1,3}$, Yong-jiu SHI ${ }^{1}$, Zhao-xin HOU ${ }^{2}$, Lu-lu LIU ${ }^{4,5}$ \\ $\left({ }^{1}\right.$ Department of Civil Engineering, Tsinghua University, Beijing 100084, China) \\ ( ${ }^{2}$ Central Research Institute of Building and Construction Co., Ltd., China Metallurgical Group Corporation, \\ Beijing 100023, China) \\ $\left({ }^{3}\right.$ Research Institute of Highway of China Ministry of Transport, Beijing 100088, China) \\ (4Institute of Chemical Machinery, Zhejiang University, Hangzhou 310027, China) \\ $\left({ }^{5}\right.$ College of Energy and Power Engineering, Nanjing University of Aeronautics and Astronautics, Nanjing 210016, China) \\ †E-mail: heminghua@tsinghua.edu.cn; heminghua07@gmail.com
}

Received Dec. 28, 2013; Revision accepted Oct. 14, 2014; Crosschecked Dec. 18, 2014

\begin{abstract}
Fiber-reinforced plastic-wrapped concrete columns (FRP-C) have been extensively used in building structures and transportation infrastructures around the world during the past two decades. These members are actually subjected to a long-term sustained axial compression before they experience the designated ultimate loading. However, little attention has been given to the performance of FRP-C after sustained axial compression compared with that of its short-term instant performance. This study aims to establish a design-oriented numerical model for the long-term deformation of circular FRP-C after sustained load. A modified constitutive model of FRP-wrapped concrete is proposed for numerical analysis of FRP-C considering two dominant effects of sustained axially compressive loading. Numerical verifications against existing tests indicates that the ultimate strength will be slightly enhanced while the ultimate strain will be conspicuously reduced in most cases of normal strength FRP-C after a long-term sustained load.
\end{abstract}

Key words: Fiber-reinforced plastic (FRP), Sustained load, Column, Long-term deformation, Creep, Constitutive model, Axial compression

doi:10.1631/jzus.A1300408

Document code: A

CLC number: TU50

\section{Introduction}

As the cost of applying fiber-reinforced plastic (FRP) in structural engineering has decreased markedly, FRP-wrapped concrete columns (FRP-C) have been widely applied worldwide in the past two

$\ddagger$ Corresponding author

* Project supported by the National Natural Science Foundation of China (Nos. 51378292, 51038006, and U1134110), the Postdoctoral Science Foundation Project of China (No. 2013M530048), the Scholarship Council Joint PhD Program of China (No. 201306210079), and the Natural Science Foundation of Beijing (No. 8144051), China

(3) ORCID: Hui LIU, http://orcid.org/0000-0003-0613-2031; Minghua HE, http://orcid.org/0000-0001-5390-7915

(C)Zhejiang University and Springer-Verlag Berlin Heidelberg 2015 decades. The behavior of FRP-C under short-term loading has been investigated in depth, and a number of models for predicting the stress strain relationship of FRP-confined concrete have been proposed by Samaan et al. (1998), Toutanji (1999), Xiao and Wu (2000), Lam and Teng (2003), Rousakis et al. (2007), and Wang and Wu (2011). These stressstrain models can be classified into two main categories: (1) design-oriented models, and (2) analysisoriented models.

While the analysis-oriented models have advantages in describing the detailed mechanical interaction between FRP laminates and the concrete core with the inevitable complexity of the 
incremental process, the design-oriented models can be much more effectively and practically used in engineering design through treating FRP-confined concrete as a single composite material, and, according to a comprehensive review and assessmen$\mathrm{t}$ of the FRP-confined concrete constitutive models including design-oriented and analysis-oriented ones (Ozbakkaloglu and Akin, 2012), the design-oriented models generally performed better in predicting ultimate strength and strain enhancement.

However, compared with the short-term assumption adopted in these previous studies, FRP-C are actually subjected to a sustained axial compression which is long-term enough in engineering application before they experience the ultimate loading, and limited attention has been paid to the effects of a sustained load on the mechanical behavior of FRP-C. Compared with the short-term analysis of FRP-C, the creep effect of concrete core and FRP laminates together with their interaction on FRP-C performance after sustained load remain uncertain. This lack of information makes it necessary to conduct further research to obtain a full understanding of this common, but generally neglected problem. A few of experimental and theoretical studies on the creep and shrinkage effects of FRP-C have been reported (Naguib and Mirmiran, 2003; Yu et al., 2003; Berthet et al., 2006; Wang et al., 2011). It has been found that the drying shrinkage strain in FRP-C is very small or eliminated due to the prevention of moisture egress in a sealed environment. Also the effect of FRP-confinement on the creep of the concrete was not very significant. Compared with FRP-C long-term deformation research, very little attention has been given to the modeling of FRP-C after sustained load. This might be due to the fact that the concrete structure strength and corresponding ultimate strain are usually not compromised by longterm deformation phenomena. However, the composite characteristics of FRP-C and the potential increase in concrete strength gained from a sustained load will make it different from what it was supposed to be. The schematic of FRP-C long-term deformation under sustained compressive load is shown in Fig. 1.

Theoretical analysis and a better understanding of this problem are far from achieved. Therefore, this study intends to establish analytical models for the long-term deformation of FRP-C and design-

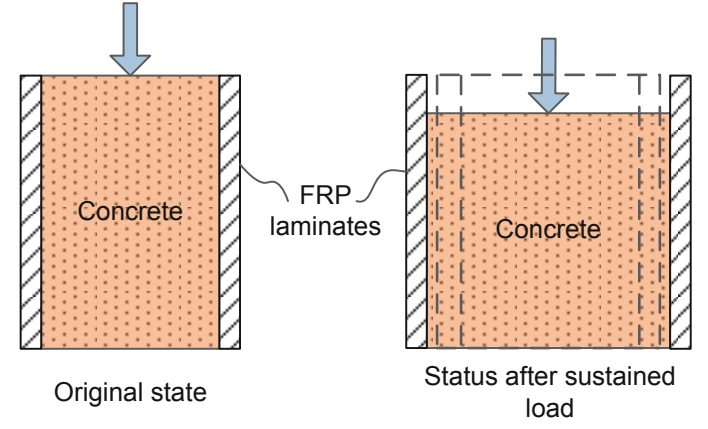

Fig. 1 Conceptual schematic of FRP-C deformation under sustained compressive loading

oriented models for FRP-C after sustained load. The development of a long-term deformation model is based on the B3 model proposed by Bazant (1995). A modified constitutive model of FRP-wrapped concrete is proposed for a numerical analysis of FRP-C considering two dominant effects of long-term sustained load. Finally, numerical verification against existing tests and a series of parametric studies are conducted to further understand the ultimate performance of FRP-C after a sustained load.

\section{Creep behavior of confined concrete}

To analyze the deformation of FRP-C under sustained compression, the confined concrete and the wrapped FRP confinement should be considered integrally. Besides the creep behavior of the concrete core and the wrapped FRP confinement, the interaction between them should be explicitly included. For simplification the case of interest, no axial stress redistribution is counted in FRP-C. The justificaion for such a simplification is that FRP-wrapped laminates only provide lateral confinement and not axial resistance.

For plain concrete, creep models are abundant. However, the creep model for FRP-wrapped concrete is limited because of its sealed condition and triaxial stress status. In this study, the B3 model originally presented by Bazant (1995) is adopted for predicting concrete core creep. The B3 model is theoretically better justified than the previous models and its coefficients of variation of deviations are very small.

The creep of a confined concrete core under sustained uniaxial compression can be calculated by the B3 model as below. The compliance function $J\left(t, t_{0}\right)$, which represents the total strain including 
elastic, shrinkage strain and creep strain at target time $t$ caused by unit axially compressive stress during loading age $t_{0}$, is given as

$$
J\left(t, t_{0}\right)=q_{1}+C_{0}\left(t, t_{0}\right)+C_{\mathrm{d}}\left(t, t_{0}, t_{\mathrm{s}}\right),
$$

where $q_{1}$ is the instantaneous strain due to unit stress, $C_{0}\left(t, t_{0}\right)$ is the compliance function for basic creep $\left(10^{-6} \mathrm{MPa}^{-1}\right), C_{\mathrm{d}}\left(t, t_{0}, t_{\mathrm{s}}\right)$ is the compliance function for simultaneous drying shrinkage $\left(10^{-6} \mathrm{MPa}^{-1}\right)$, and $t_{\mathrm{s}}$ is the age when shrinkage begins. As to confined concrete with sealed curing, the drying creep and shrinkage can be neglected owing to the effective prevention of moisture loss. Then only the basic creep needs to be taken into account, so the compliance function can be simplified to

$$
\begin{aligned}
C_{0}\left(t, t_{0}\right)= & q_{2} Q\left(t, t_{0}\right)+q_{3} \ln \left[1+\left(t-t_{0}\right)^{l}\right] \\
& +q_{4} \ln \left(\frac{t}{t_{0}}\right)
\end{aligned}
$$

where $q_{2}, q_{3}$, and $q_{4}$ are the aging viscoelastic compliance, non-aging viscoelastic compliance, and flow compliance concerning the material parameters of concrete, respectively, as deduced from solidification theory (Bazant and Prasannan, 1989). $Q\left(t, t_{0}\right)$ is a function concerning the age at loading which can be easily obtained from an approximate explicit formula or numerical integration, while $l$ is an empirical parameter whose value can be taken as 0.1 for all normal concrete.

With the creep of the concrete core in composite columns like FRP-C, hoop stress may vary over time due to the lateral static equilibrium and geometric compatibility. To account for variable stresses in concrete, the Boltzmann principle of superposition can be used (Mayfield, 1983). Therefore, the total strain due to a variable stress history can be obtained by integrating the strains responded to small stress increments applied at small time intervals.

$$
\varepsilon(t)=\sum_{i=1}^{n} 0.5\left[J\left(t_{n}, t_{i}\right)+J\left(t_{n}, t_{i-1}\right)\right] \Delta \sigma\left(t_{i}\right),
$$

where the subscripts $n$ and $i$ refer to the total and individual time steps for numerical integration, respectively, and $\Delta \sigma\left(t_{i}\right)$ refers to the $i$ th stress incremental step. The application of the Boltzmann principle of superposition is appropriate for a deformation response in the linear range, so the linear creep assumption is introduced.
The triaxial stress status is another highlighted characteristic of confined concrete. It is known that the net creep strain under triaxial stress can be less than that under a uniaxial stress of the same magnitude. Gopalakrishnan et al. (1970) showed that despite anisotropy and creep nonlinearity, creep strain in concrete under triaxial stress conforms to the Boltzmann principle of superposition. Therefore, the total creep strain in any direction can be obtained by adding all its portions caused by each stress composition acting separately, and its total axial creep strain and radial creep strain can be calculated by

$$
\begin{aligned}
& \varepsilon_{\mathrm{c} 1}(t)=J\left(t, t_{0}\right) \sigma_{\mathrm{c} 1}-2 \mu_{\mathrm{c}} J\left(t, t_{0}\right) \sigma_{\mathrm{c} 3}, \\
& \varepsilon_{\mathrm{c} 2}(t)=\mu_{\mathrm{epr}} \varepsilon_{\mathrm{c} 1}(t),
\end{aligned}
$$

where $\sigma_{\mathrm{c} 1}$ is the axial stress in the concrete core $(\mathrm{MPa}), \sigma_{\mathrm{c} 3}$ is the hoop stress in the concrete core $(\mathrm{MPa}), \mu_{\mathrm{c}}$ is the static Poisson's ratio of concrete, and $\mu_{\text {epr }}$ is the effective creep Poisson's ratio. According to Gopalakrishnan et al. (1970) and Jordaan and Illston (1971), the effective creep Poisson's ratio $\mu_{\text {epr }}$ under the triaxial state can be assumed to remain constant over time.

\section{Creep behavior of wrapped FRP}

Creep sources in FRP laminates include creep of fibers, creep of resin, and creep due to fiber straightening. The power law relationship established by Findley (1960) has been widely accepted and used for predicting the creep behavior of FRP laminates under constant uniaxial stress.

$$
\begin{aligned}
\varepsilon_{\mathrm{f}} & =\varepsilon_{0}^{\prime}+\varepsilon_{\mathrm{t}}^{\prime} t_{\mathrm{l}}^{m}, \\
\varepsilon_{\mathrm{t}}^{\prime} & =\varepsilon_{\mathrm{t}} \sinh \frac{\sigma}{\sigma_{\mathrm{t}}},
\end{aligned}
$$

where $\varepsilon_{\mathrm{f}}$ is the total elastic and creep strain of FRP laminates (MPa), $\varepsilon_{0}^{\prime}$ is the elastic strain, $\varepsilon_{\mathrm{t}}^{\prime}$ is the time-dependent strain coefficient, $t_{1}$ is the time after loading (h), $\sigma$ is the constant stress in FRP laminates, and $m, \varepsilon_{\mathrm{t}}$, and $\sigma_{\mathrm{t}}$ are the empirical material constants. For three different types of FRP laminates, these parameters are given as: $m=0.123$, 0.129 , and $0.061 ; \varepsilon_{\mathrm{t}}=0.0011,0.1112$, and 0.0387 for carbon FRP (CFRP), aramid FRP (AFRP), and glass FRP (GFRP), respectively; and $\sigma_{\mathrm{t}}=68950$ for all cases (Naguib, 2001). 
When it comes to the variable stress history, the strain in FRP laminates also follows the Boltzmann principle of superposition. It was modified by Findley (1960) to include the possible nonlinearity of FRP as follows:

$$
\begin{aligned}
\varepsilon_{\mathrm{f}}= & \varepsilon_{0}^{\prime}+\varepsilon_{\mathrm{t}}\left(\sinh \frac{\sigma}{\sigma_{\mathrm{t}}}\right) t_{\mathrm{l}}^{m} \\
& +\varepsilon_{\mathrm{t}}\left(\sinh \frac{\Delta \sigma}{\sigma_{\mathrm{t}}}\right) \Delta t_{\mathrm{l}}^{m},
\end{aligned}
$$

where $\Delta \sigma$ is the change of stress in time increment $\Delta t_{1}$. This approximation is accurate when the stress ratios $\sigma / \sigma_{0}$ and $\sigma / \sigma_{\mathrm{t}}$ are within the range of service loads.

\section{Integrated creep of FRP-C}

Based on knowledge of creep of confined concrete and wrapped FRP, integrated deformation of FRP-C with long-term deformation characteristics is obtained. The so-called integrated deformation modelling originates from two fundamental relations including static equilibrium and geometric compatibility in the hoop direction.

\subsection{Interaction of wrapped FRP and concrete}

As shown in Fig. 2, in the lateral direction, the static equilibrium condition is

$$
\sigma_{\mathrm{c} 3}=\frac{2 t_{\mathrm{f}}}{D}+\sigma_{\mathrm{f} 3},
$$

where $\sigma_{\mathrm{f} 3}$ is the hoop stress of the FRP laminates, and $t_{\mathrm{f}}$ and $D$ are the thickness of the FRP laminates and the outer diameter, respectively. Given the assumption that the concrete core and the FR$\mathrm{P}$ laminates are perfectly bonded during the whole loading process, the radial strain in concrete must be equal to the hoop strain in FRP.

$$
\varepsilon_{\mathrm{c} 3}=\varepsilon_{\mathrm{f} 3},
$$

where $\varepsilon_{\mathrm{c} 3}$ and $\varepsilon_{\mathrm{f} 3}$ are the radial strain in the concrete and the hoop strain in the FRP, respectively.

The analysis procedure for the long-term deformation of FRP-C can be divided into two main steps: initial short-term static analysis and long-term creep analysis. The initial short-term static stresses and strains are determined at loading age $t_{0}$ based on the two main requirements stated above.

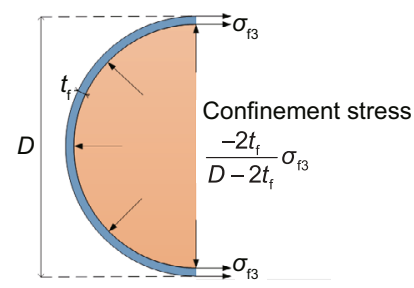

Fig. 2 Schematic presentation of FRP-C section and its lateral stress equilibrium

The axial stress in concrete can be calculated with a given long-term sustained load $N_{\mathrm{L}}$ and concrete sectional area $A_{\mathrm{c}}$.

$$
\sigma_{\mathrm{c} 1}\left(t_{0}\right)=\frac{N_{\mathrm{L}}}{A_{\mathrm{c}}}
$$

Here the short-term exponential stress-strain constitutive model proposed by Liu et al. (2013) for FRP-confined concrete core is used to calculate the axial strain in concrete $\varepsilon_{\mathrm{c} 1}\left(t_{0}\right)$ with initial $\sigma_{\mathrm{c} 1}\left(t_{0}\right)$. The hoop strain in FRP laminates $\varepsilon_{\mathrm{f} 3}\left(t_{0}\right)=\varepsilon_{\mathrm{c} 3}\left(t_{0}\right)=\mu_{\mathrm{c}} \varepsilon_{\mathrm{c} 1}\left(t_{0}\right)$ and its corresponding hoop stress $\sigma_{\mathrm{f} 3}\left(t_{0}\right)=\mu_{\mathrm{c}} \varepsilon_{\mathrm{c} 1}\left(t_{0}\right) E_{\mathrm{f}}$ can be obtained, where $E_{\mathrm{f}}$ is the elastic modulus of FRP. Then the initial radial stress in the concrete core can be calculated through a lateral static equilibrium as

$$
\sigma_{\mathrm{c} 3}\left(t_{0}\right)=\mu_{\mathrm{c}} \frac{2 t_{\mathrm{f}}}{D} \varepsilon_{\mathrm{c} 1}\left(t_{0}\right) E_{\mathrm{f}} .
$$

Once the initial stresses in both the concrete core and the FRP laminates have been determined, the long-term deformation analysis of FRP-C can be performed. As the final result at target time $t$ instead of the whole process of deformation is emphasized in this study, there is no analysis of deformation versus time here. The calculation of the long-term creep of a concrete core and FRP laminates can be simplified as follows:

$$
\begin{aligned}
& \varepsilon_{\mathrm{c} 1}(t)=J\left(t, t_{0}\right) \sigma_{\mathrm{c} 1}\left(t_{0}\right)-2 \mu_{\mathrm{c}} J\left(t, t_{0}\right) \frac{\sigma_{\mathrm{c} 3}(t)+\sigma_{\mathrm{c} 3}\left(t_{0}\right)}{2}, \\
& \varepsilon_{\mathrm{f} 3}(t)=\frac{\sigma_{\mathrm{f} 3}(t)}{E_{\mathrm{f}}}+\frac{1}{2}\left(\sinh \frac{\sigma_{\mathrm{f} 3}(t)}{\sigma_{\mathrm{t}}}+\sinh \frac{\sigma_{\mathrm{f} 3}\left(t_{0}\right)}{\sigma_{\mathrm{t}}}\right) t_{\mathrm{f}}^{n},
\end{aligned}
$$

where $\varepsilon_{\mathrm{c} 1}(t)$ is the axial strain in concrete core at the target time $t, \varepsilon_{\mathrm{f} 3}(t)$ is the hoop stain in FRP laminates at the target time $t, \sigma_{\mathrm{c} 1}\left(t_{0}\right)$ and $\sigma_{\mathrm{c} 3}\left(t_{0}\right)$ are the axial strain and radial strain in concrete core at loading age, respectively, $\sigma_{\mathrm{c} 3}(t)$ is the radial 
strain in concrete core at target time $t$, and $\sigma_{\mathrm{f3}}(t)$ and $\sigma_{\mathrm{f} 3}\left(t_{0}\right)$ are the hoop strain in FRP laminates at target time and loading age, respectively. Here the FRP laminates are assumed to remain elastic, and the radial strain of the concrete core can be obtained as $\varepsilon_{\mathrm{c} 3}(t)=\mu_{\mathrm{c}} \varepsilon_{\mathrm{c} 1}(t)$. The trial values of $\sigma_{\mathrm{c} 3}(t)$ and $\sigma_{\mathrm{f} 3}(t)$ can be estimated as $\sigma_{\mathrm{c} 3}\left(t_{0}\right)$ and $\sigma_{\mathrm{f} 3}\left(t_{0}\right)$ first, then be obtained through the iterative calculation stated below.

\subsection{Iterative procedure for FRP-C creep}

According to the geometric compatibility, we check the difference between the hoop strain in FRP $\varepsilon_{\mathrm{f} 3}(t)$ and the radial strain in concrete $\varepsilon_{\mathrm{c} 3}(t)$. If it is greater than the preset tolerance, we make the new value of $\varepsilon_{\mathrm{c} 3}(t)$ equal to the value of $\varepsilon_{\mathrm{f} 3}(t)$, and update the new value of $\sigma_{\mathrm{c} 3}(t)$ with Eq. (14) accordingly. In addition to the static equilibrium in the hoop direction, the updated hoop stress in $\operatorname{FRP} \sigma_{\mathrm{f} 3}(t)$ can be calculated as

$$
\sigma_{\mathrm{f} 3}(t)=\frac{D}{2 t_{\mathrm{f}}} \sigma_{\mathrm{c} 3}(t) .
$$

In this way, the whole iterative procedure of long-term deformation analysis for FRP-C is repeated until convergence is achieved. The flow chart for analyzing the long-term deformation of FRP-C at target time $t$ is illustrated in Fig. 3, where tolerance limit $\xi \geq 0$.

\subsection{Validation of iterative procedure}

The accuracy of the proposed long-term deformation analysis method is validated in this section. We choose the long-term deformation test data reported by Naguib and Mirmiran (2003) and Yu et al. (2003) as the benchmarks, with the corresponding geometric and material parameters listed in Table 1. As to the labelling of the specimens, the first letter $\mathrm{S}$ or $\mathrm{L}$ denotes the short-term or long-term, the second number denotes the specimen group, and the last number denotes the long-term load ratio $r . f_{\mathrm{c} 0}$ denotes the plain concrete strength.

The total axial strain of a concrete core is predicted by the simplified analytical method proposed in Section 4.2. The predicted axial strains are plotted against the experimental observations with different long-term load ratios in Figs. 4a, 4b, and 4c, respectively. It appears that the total axial strain estimated by the proposed analytical method is in

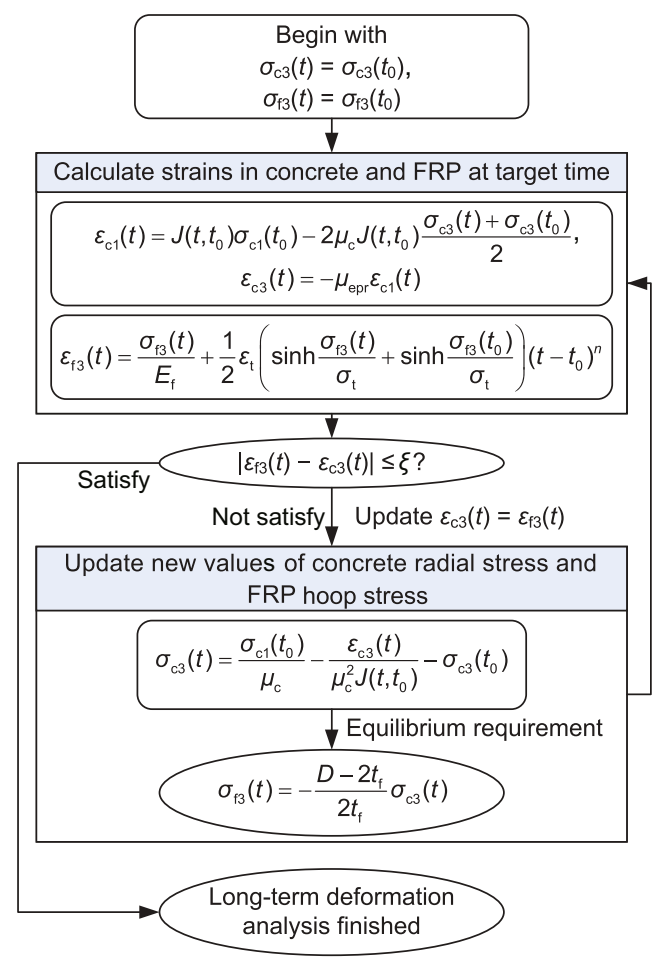

Fig. 3 Flow chart of creep effect analysis for FRP-C

good agreement with experimental results with different sustained load ratios. Even though a slight overestimation may be found in some cases, it will lead to a relatively conservative design according to the mechanical analysis. Therefore, the simplified analytical model for FRP-C long-term deformation can be reliably used in practical design.

\section{FRP-C under sustained compression}

Based on the long-term deformation analysis presented above, we can subsequently deduce the constitutive models for FRP-confined concrete after creep to make the analysis of FRP-C after sustained load more theoretical and convincing. Three effects of sustained load on FRP-C ultimate performance will be discussed here, and the modeling of FRP-C after sustained load is then elaborated accordingly.

\subsection{Short-term constitutive models of FRP-C concrete}

\subsubsection{Stress-strain envelope}

Extensive experimental studies have shown that the stress-strain curve of concrete uniformly 
Table 1 Basic information of selected test members in numerical verification

\begin{tabular}{lccccccc}
\hline Specimen number & $N_{\mathrm{L}}(\mathrm{kN})$ & $t-t_{0}(\mathrm{~d})$ & $f_{\mathrm{c} 0}(\mathrm{MPa})$ & $\varepsilon_{\text {frp }}(\%)$ & $E_{\mathrm{f}}(\mathrm{mm})$ & $t_{\mathrm{f}}(\mathrm{mm})$ & $D(\mathrm{~mm})$ \\
\hline S-1 & 0 & 0 & 29.0 & 2.3 & 26135 & 2 & 152 \\
L-1-0.15 & 178 & 100 & 29.0 & 2.3 & 26135 & 2 & 152 \\
S-2 & 0 & 0 & 43.2 & 1.2 & 118000 & 0.222 & 100 \\
L-2-0.30 & 150 & 160 & 43.2 & 1.2 & 118000 & 0.222 & 100 \\
L-2-0.60 & 300 & 160 & 43.2 & 1.2 & 118000 & 0.222 & 100 \\
\hline
\end{tabular}
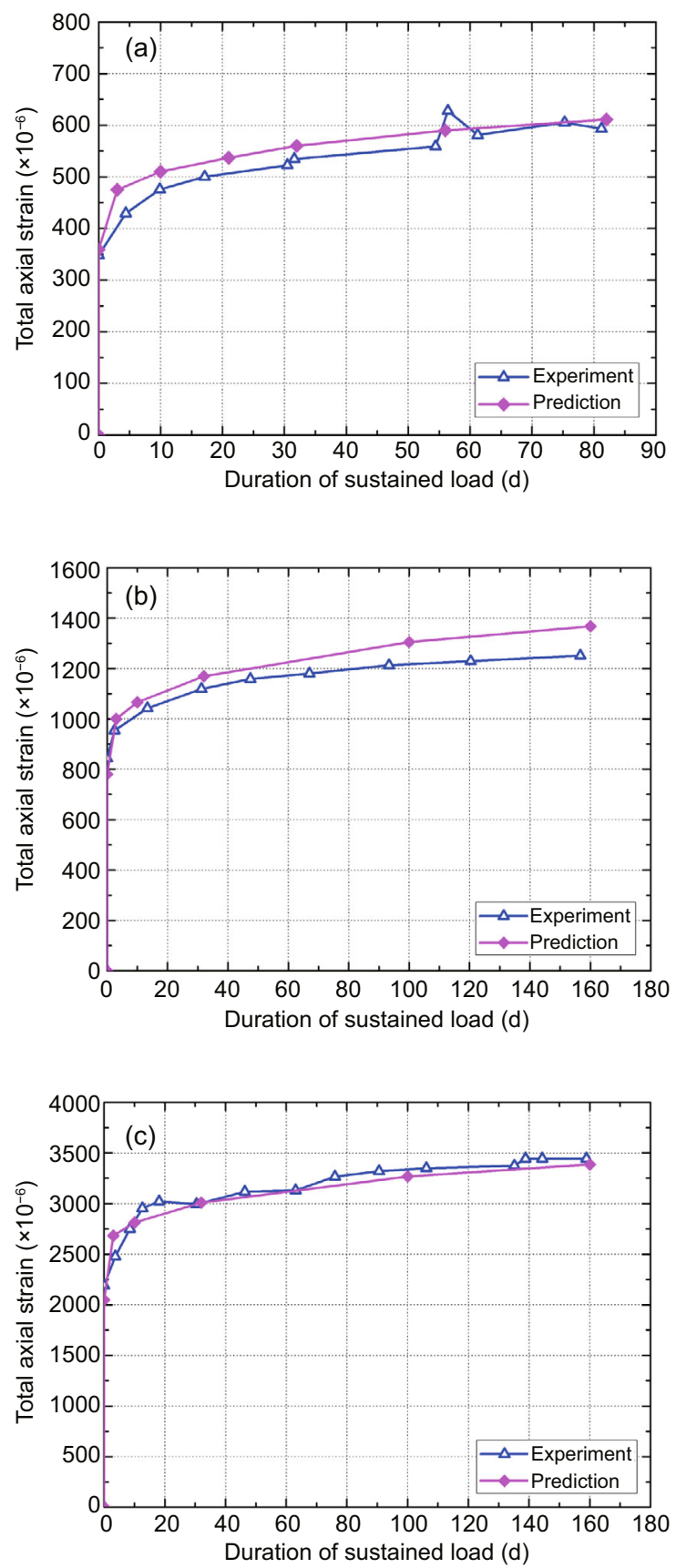

Fig. 4 Validation of FRP-C long-term deformation model: (a) $r=0.15$; (b) $r=0.30$; (c) $r=0.60$ confined with FRP shows a monotonically ascending shape (the increasing type) if the confinement provided by the FRP laminate exceeds a threshold. For such FRP-confined concrete, both the compressive strength and the ultimate axial strain are reached simultaneously and are significantly enhanced. Otherwise, a postpeak descending branch can be expected and the compressive strength is reached before rupture of the FRP laminate (the decreasing type). This phenomenon is mainly caused by the lack of confinement, and the degree of confinement offered by FRP laminates can be represented by the confinement ratio $\alpha$ which is defined as the ratio of the maximum confining pressure to the un-confined concrete compressive strength.

As mentioned above, the FRP-confined concrete model proposed by Liu et al. (2013) was adopted in determining the short-term stress-strain relationship here. It is a modified model based on the prevalent Lam-Teng's model (Lam and Teng, 2003), and the envelope curve can be expressed as a combination of a parabola first branch and a linear second branch as shown in Fig. 5.

$$
\sigma_{\mathrm{c}}= \begin{cases}E_{\mathrm{c}} \varepsilon_{\mathrm{c}}-\frac{\left(E_{\mathrm{c}}-E_{2}\right)^{2}}{4 f_{0}} \varepsilon_{\mathrm{c}}^{2}, & 0 \leq \varepsilon_{\mathrm{c}} \leq \varepsilon_{\mathrm{tp}} \\ f_{0}+E_{2} \varepsilon_{\mathrm{c}}, & \varepsilon_{\mathrm{tp}}<\varepsilon_{\mathrm{c}} \leq \varepsilon_{\mathrm{cu}}\end{cases}
$$

The transition point strain $\varepsilon_{\mathrm{tp}}$ and the linear portion $E_{2}$ are given as

$$
\begin{aligned}
\varepsilon_{\mathrm{tp}} & =\frac{2 f_{0}}{E_{\mathrm{c}}-E_{2}}, \\
E_{2} & =\frac{f_{\mathrm{cc}}-f_{0}}{\varepsilon_{\mathrm{cu}}}
\end{aligned}
$$

where $E_{\mathrm{c}}=4750 \sqrt{f_{\mathrm{c} 0}}$ is the elastic modulus of concrete, $f_{0}$ is the stress axial intercept and $f_{0}=1.1 f_{\mathrm{c} 0}^{\prime}$ can be adopted here for simplicity according to statistical study, and $f_{\mathrm{cc}}$ and $\varepsilon_{\mathrm{cu}}$ are the ultimate strength and ultimate strain of the FRP-confined concrete, respectively. 


\subsubsection{Ultimate stress and ultimate strain}

Based on the general shape of the stress-strain curve described above, the determination of the ultimate strength $f_{\text {cc }}$ and the ultimate strain $\varepsilon_{\text {cu }}$ are critical to constitutive model. Eventual failure occurs when the FRP jacket ruptures as a result of tensile stresses in the hoop direction. The actual maximum confining pressure $f_{1, \mathrm{a}}$ is assumed to be controlled by the FRP rupture strain $\varepsilon_{\mathrm{h} \text {,rup instead of }}$ the ultimate strain $\varepsilon_{\text {frp }}$ achieved in a tensile coupon test, and it can be much smaller than the ideal maximum confining pressure $f_{1}$. In this way, a so-called FRP strain reduction factor $k_{\varepsilon}$ is defined to describe the ratio between $\varepsilon_{\mathrm{h}, \text { rup }}$ and $\varepsilon_{\text {frp }}$ as

$$
\begin{gathered}
k_{\varepsilon}=\frac{\varepsilon_{\mathrm{h}, \mathrm{rup}}}{\varepsilon_{\text {frp }}}, \\
f_{\mathrm{l}, \mathrm{a}}=k_{\varepsilon} f_{\mathrm{l}}=\frac{2 E_{\mathrm{f}} t_{\mathrm{f}} \varepsilon_{\mathrm{h}, \mathrm{rup}}}{D} .
\end{gathered}
$$

As previously reported by Ozbakkaloglu and Akin (2012), an increase of plain concrete strength $f_{\mathrm{c} 0}$ and elastic modulus of FRP $E_{\mathrm{f}}$ both have an adverse influence on $\varepsilon_{\mathrm{h}, \mathrm{rup}}$. Based on multivariate regression analysis covering 976 FRPconfined specimens during last two decades (Lim and Ozbakkaloglu, 2014), the expression of FRP rupture strain can be statistically quantified for FRP types including CFRP, GFRP, AFRP, and high-modulus CFRP (HM CFRP) as follows:

$$
k_{\varepsilon}=0.9-2.3 f_{\mathrm{c} 0} \times 10^{-3}-0.75 E_{\mathrm{f}} \times 10^{-6},
$$

where $f_{\mathrm{c} 0}$ and $E_{\mathrm{f}}$ are in $\mathrm{MPa}$, and $1 \times 10^{5} \mathrm{MPa} \leq$ $E_{\mathrm{f}} \leq 6.4 \times 10^{5} \mathrm{MPa}$.

The circular section FRP-C can be regarded as a basic case due to its uniform confinement provided

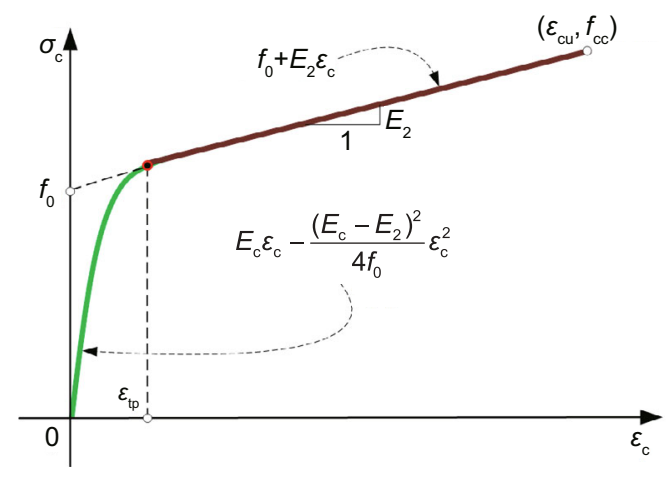

Fig. 5 Envelope curve for FRP-confined concrete by FRP laminates, where no shape factors need to be introduced in comparison with rectangular sectional FRP-C. Its ultimate axial strain can be determined as

$$
\frac{\varepsilon_{\mathrm{cu}}}{\varepsilon_{\mathrm{c} 0}}=c_{2}+k_{2} \frac{K_{1}}{f_{\mathrm{c} 0}} \frac{\varepsilon_{\mathrm{h}, \mathrm{rup}}^{1.35}}{\varepsilon_{\mathrm{c} 0}} .
$$

According to the study of a combined database that covers unconfined concrete strength ranging from 6.2 MPa to 169.7 MPa (Lim and Ozbakkaloglu, 2013), the strain enhancement coefficient $k_{2}=0.263$ is suggested and the normalized ultimate strain coefficient $c_{2}$ can be statistically determined as

$$
c_{2}=2-0.01\left(f_{\mathrm{c} 0}-20\right), \quad c_{2} \geq 1 .
$$

As to the expression of ultimate strength, $k_{1}=3.18$ is suggested (Lam and Teng, 2003), and a definition of FRP stiffness threshold $k_{10}$ needs to be introduced. It is a minimum threshold for FRP confinement stiffness $K_{1}$ to make FRP-confined concrete exhibit a monotonic ascent; otherwise a postpeak strain softening will happen due to insufficient confinement.

$$
\begin{gathered}
K_{\mathrm{l}}=\frac{2 E_{\mathrm{f}} t_{\mathrm{f}}}{D}, \\
K_{10}=f_{\mathrm{c} 0}^{1.65}, \\
\frac{f_{\mathrm{cc}}}{f_{\mathrm{c} 0}}=c_{1}+k_{1} \frac{f_{\mathrm{l}, \mathrm{a}}-f_{10}}{f_{\mathrm{c} 0}},
\end{gathered}
$$

where $K_{10}$ is defined as the threshold for FRP confinement stiffness to exhibit a monotonic ascent. If $K_{1} \geq K_{10}$,

$$
\begin{gathered}
c_{1}=1+0.0058 \frac{K_{1}}{f_{\mathrm{c} 0}}, \\
\varepsilon_{11}=\left(0.43+0.009 \frac{K_{1}}{f_{\mathrm{c} 0}}\right) \varepsilon_{\mathrm{c} 0}, \\
f_{10}=K_{\mathrm{l}} \varepsilon_{11} .
\end{gathered}
$$

If $K_{1}<K_{10}$,

$$
\begin{gathered}
c_{1}=\left(\frac{K_{\mathrm{l}}}{f_{\mathrm{c} 0}^{1.6}}\right)^{0.2} \\
\varepsilon_{11}=24\left(\frac{f_{\mathrm{c} 0}}{K_{\mathrm{l}}^{1.6}}\right)^{0.4} \varepsilon_{\mathrm{c} 0},
\end{gathered}
$$

$$
f_{10}=K_{1} \varepsilon_{11}
$$




\subsection{Effects of sustained load on FRP-C}

Sustained axial loads make the performance of FRP-C different from that with short-term ones. The main reasons for this differences are the extra residual hoop strain in the FRP laminates caused by creep behavior of the concrete core and FRP, and the potential benefits of concrete strength.

\subsubsection{Residual hoop strain in FRP due to creep}

The creep recovery of concrete is assumed to be negligible in this study. This assumption is consistent with common situations in practice: extreme loading usually takes place right after the service load and the time interval between them is short enough to neglect creep recovery. Creep deformation could develop during the service life of FRP-C and an irreversible residual hoop strain in FRP laminates would exist due to the compatibility of deformation. The residual hoop strain $\check{\varepsilon}_{\mathrm{f} 3}$ at target time $t$ can be expressed as

$$
\begin{gathered}
\check{\varepsilon}_{\mathrm{f} 3}=\check{\varepsilon}_{\mathrm{c} 3}=\left|-\mu_{\mathrm{epr}} \check{\varepsilon}_{\mathrm{c} 1}\right|, \\
\check{\varepsilon}_{\mathrm{c} 1}=\varepsilon_{\mathrm{c} 1}(t)-\varepsilon_{\mathrm{c} 1}\left(t_{0}\right),
\end{gathered}
$$

where $\check{\varepsilon}_{\mathrm{c} 1}$ and $\check{\varepsilon}_{\mathrm{c} 3}$ are the residual axial strain and the residual radial strain in the concrete, respectively. Here, we adopt a linear formula to characterize the reduction of effective confinement strength, so the reserved confinement strength provided by FRP wrapped laminates can be calculated as

$$
\tilde{f}_{\mathrm{l}, \mathrm{a}}=\frac{\varepsilon_{\mathrm{h}, \mathrm{rup}}-\check{\varepsilon}_{\mathrm{f} 3}}{\varepsilon_{\mathrm{h}, \text { rup }}} f_{\mathrm{l}, a}<f_{\mathrm{l}, a} .
$$

This means that the effective confinement strength $\tilde{f}_{1, \text { a }}$ provided by FRP laminates will decrease after a long-term sustained load. Negative influences of the residual hoop strain in FRP on both the ultimate strength and the ultimate strain of FRP-C can be expected.

5.2.2 Enhanced plain concrete strength due to sustained load

The compressive strength of plain concrete after sustained load (axial compression in this case) is assumed to be moderately higher than that of the short-term counterpart here. This assumption is emphasized, because this possible beneficial gain in concrete strength has been observed in many experimental studies for normal strength concrete. Hughes and Ash (1970) found that concrete strength after sustained load increases with decreasing concrete age, increasing cement content, and increasing aggregate size, which all result in a greater creep in concrete. Dhir and Sangha (1972) conducted a review on this problem, and proposed that this enhancement was about $11 \%$ for 28 -d tests. This phenomenon could be induced by increased consolidation of concrete (Coutinho, 1977) and by improved healing of cracks perpendicular to the load (Hellesland et al., 1972). Based on the experimental results stated above, we introduce an enhancement coefficient $k_{\mathrm{c} 0} \geq 1$ to characterize plain concrete strength after a long-term sustained load:

$$
\tilde{f}_{\mathrm{c} 0}=k_{\mathrm{c} 0} f_{\mathrm{c} 0} .
$$

5.2.3 Modified constitutive model of FRP-confined concrete after a sustained load

Based on the effects of a sustained load on FRPC stated in Section 5.2.2, we can further depict the mechanism from the perspective of a constitutive model.

The ultimate stress of FRP-confined concrete may either be increased or decreased after long-term sustained load. The coupling effects of the increase in plain concrete strength and the decrease in confinement strength compete with each other to determine the change of ultimate strength of confined concrete. The specific value of the strength change is dependent on the material and geometric properties of FRP-C and the level and duration of sustained load. By means of the general analytical model established in this study, the seemingly divergent observation on the strength change of confined concrete caused by sustained load can be well explained and characterized here.

With respect to the ultimate strain after sustained load $\tilde{\varepsilon}_{\mathrm{cu}}$, it will be smaller than the ultimate strain of the corresponding short-term counterpart $\varepsilon_{\mathrm{cu}}$. This trend can be clearly seen from Eqs. (21) and (22), where the enhanced plain concrete strength $\tilde{f}_{\mathrm{c} 0}$ and its corresponding decreased $k_{\varepsilon}$ will lower the value of the ultimate strain.

Substituting $f_{\mathrm{c} 0}$ and $f_{\mathrm{l}, \mathrm{a}}$ in Eqs. (26) and (22) with $\tilde{f}_{\mathrm{c} 0}$ and $\tilde{f}_{\mathrm{l}, \mathrm{a}}$, the ultimate stress and strain after 
sustained load can be calculated as follows:

$$
\begin{gathered}
\tilde{f}_{\mathrm{cc}}=\tilde{c}_{1} \tilde{f}_{\mathrm{c} 0}+k_{1}\left(\tilde{f}_{\mathrm{l}, \mathrm{a}}-\tilde{f}_{\mathrm{l} 0}\right), \\
\tilde{\varepsilon}_{\mathrm{cu}}=\tilde{c}_{2} \varepsilon_{\mathrm{c} 0}+k_{2}\left(\frac{K_{\mathrm{l}}}{\tilde{f}_{\mathrm{c} 0}}\right) \tilde{\varepsilon}_{\mathrm{h}, \mathrm{rup}}^{1.35} .
\end{gathered}
$$

We modify the short-term constitutive model with newly estimated parameters and horizontal coordinates translation of residual axial strain of concrete $\check{\varepsilon}_{\mathrm{c} 1}$, by which the aforementioned effects of a longterm sustained load can be accounted for. The proposed modified constitutive model after a sustained load can be expressed by

$$
\sigma_{\mathrm{c}}= \begin{cases}0, & -\check{\varepsilon}_{\mathrm{c} 1} \leq \varepsilon_{\mathrm{c}}^{*}<0, \\ \tilde{E}_{\mathrm{c}} \varepsilon_{\mathrm{c}}^{*}-\frac{\left(\tilde{E}_{\mathrm{c}}-\tilde{E}_{2}\right)^{2}}{4 \tilde{f}_{0}} \varepsilon_{\mathrm{c}}^{* 2}, & 0 \leq \varepsilon_{\mathrm{c}}^{*}<\tilde{\varepsilon}_{\mathrm{tp}}, \\ \tilde{f}_{0}+\tilde{E}_{2} \varepsilon_{\mathrm{c}}^{*}, & \tilde{\varepsilon}_{\mathrm{tp}} \leq \varepsilon_{\mathrm{c}}^{*}<\tilde{\varepsilon}_{\mathrm{cu}},\end{cases}
$$

where $\varepsilon_{\mathrm{c}}^{*}=\varepsilon_{\mathrm{c}}-\check{\varepsilon}_{\mathrm{c} 1}$, the modified concrete elastic modulus $\tilde{E}_{\mathrm{c}}=4750 \sqrt{\tilde{f}_{\mathrm{c} 0}}$ and intercept $\tilde{f}_{0}=1.1 \tilde{f}_{\mathrm{c} 0}$, while the modulus of the linear branch and the strain in the transit point can be calculated as

$$
\begin{aligned}
& \tilde{E}_{2}=\frac{\tilde{f}_{\mathrm{cc}}-\tilde{f}_{0}}{\tilde{\varepsilon}_{\mathrm{cu}}}, \\
& \tilde{\varepsilon}_{\mathrm{t}}=\frac{2 \tilde{f}_{0}}{\tilde{E}_{\mathrm{c}}-\tilde{E}_{2}} .
\end{aligned}
$$

The comparison between the short-term constitutive model of FRP-wrapped concrete and the modified one after sustained load of FRP-C is schematically illustrated in Fig. 6.

\section{Numerical validation}

Based on the design-oriented models proposed above for FRP-C subjected to sustained compression, the numerical validation for the effectiveness of the proposed model is reported and discussed. In the numerical validations, the following modeling assumptions based on the OpenSees fiber element method were made:

1. The strain-stress relationship presented in Section 5 is adopted for predicting the behavior of FRP-confined concrete;

2. The original plane cross-sections remain plane during the whole analysis process;

3. The relative slippage between the concrete core and the FRP laminates is omitted;

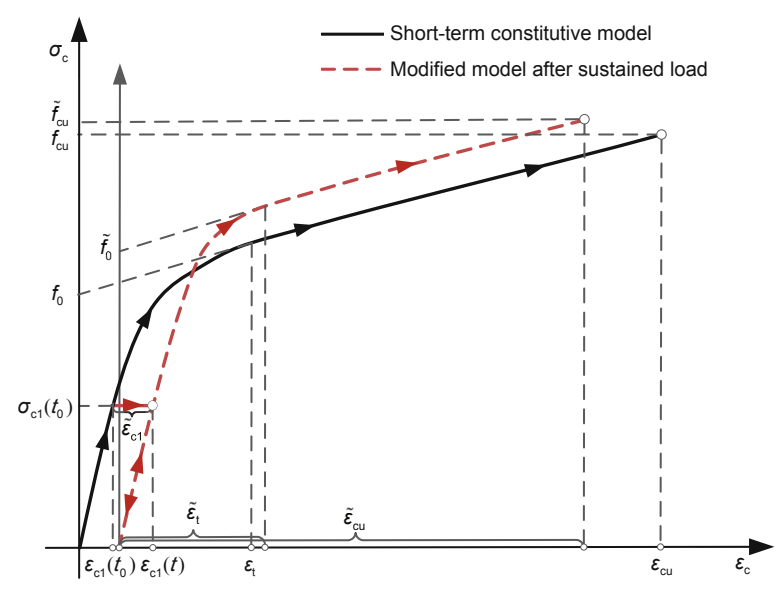

Fig. 6 Short-term model and modified model after sustained load of FRP-C

4. The contribution of concrete to tension is neglected;

5. The plain concrete strength enhancement coefficient is assumed to be 1.1 according to previous analogous tests (Cook and Chindaprasirt, 1980).

Long-term tests were introduced first on specimens L-1 and L-2 for $100 \mathrm{~d}$ and $162 \mathrm{~d}$, respectively, while specimens S-1 and S-2 were kept unloaded for the whole duration. Then all the specimens were further loaded to failure to investigate the influence of time effects on the ultimate capacity of FRP-C. In the long-term deformation tests, the deformation increased at a greater rate in the first couple of weeks and then gradually became constant. Then with the results of ultimate axial loading tests, the comparison with the stress-strain curves of corresponding specimens was illustrated. It can be found that the failure patterns were identical and were characterized by shear fracture of the wrap in the middle third of the specimen height and along fiber direction. It is interesting that no strength degradation was noted for the FRP-C after sustained load, instead the strength was moderately enhanced. As to the ultimate strain, the reserved deformation capacity of FRP-C was much reduced by long-term sustained load compared with its short-term counterparts as indicated by the value of the experimental ultimate strength $\sigma_{\mathrm{uE}}$ and ultimate strain $\varepsilon_{\mathrm{uE}}$.

The numerical results of all specimens were compared with the experimental results in Fig. 7 and Table 2. $\sigma_{\mathrm{uN}}$ and $\varepsilon_{\mathrm{uN}}$ are the numerical ultimate strength and numerical ultimate strain, respectively. It can be seen that the model gave good 
predictions of the ultimate condition for most FRP-C specimens. The numerical load-deformation curves indicated a satisfactory and relatively conservative correlation with the experimental curves during the whole process. The numerical results of L-1 and L-2 also showed a moderate greater ultimate strength and a much smaller peak strain than those of S-1 and S-2, respectively, consistent with the test studies (Naguib, 2001; Yu et al., 2003) and theoretical analysis proposed in this study. According to the experimental and numerical results, the effects of a sustained load on ultimate strength were not as significant as the effect on ultimate strain. The main reason is that two main effects of sustained load stated above have opposite influences on the ultimate strength, while they both decrease the deformation capacity.

Table 2 Numerical results and the comparison with experimental results

\begin{tabular}{lcccc}
\hline Specimen & $\sigma_{\mathrm{uN}}(\mathrm{MPa})$ & $\sigma_{\mathrm{uE}}(\mathrm{MPa})$ & $\varepsilon_{\mathrm{uE}}(\%)$ & $\varepsilon_{\mathrm{uN}}(\%)$ \\
\hline S-1 & 71.69 & 68.06 & 3.93 & 3.30 \\
$\mathrm{~L}-1-0.15$ & 71.72 & 70.22 & 2.76 & 2.95 \\
S-2 & 65.45 & 54.91 & 0.84 & 0.83 \\
L-2-0.30 & 66.16 & 58.28 & 0.74 & 0.68 \\
L-2-0.60 & 65.72 & 58.13 & 0.61 & 0.72 \\
\hline
\end{tabular}

\section{Conclusions}

A designed-oriented analytical model for longterm deformation of FRP-C and a proposed modified constitutive model of FRP-confined concrete after sustained compression have been proposed. Verifications for the proposed models have been carefully carried out, and the results are in a good agreement with experimental data. Several conclusions and remarks can be summarized as follows:

1. A design-oriented analytical model was established for highly efficient estimation of long-term deformation in FRP-wrapped composite columns at any designated target time. The whole procedure of the iterative calculation has been elaborated, and the model validation has been conducted with existing experimental data. It can be used as an efficient and general framework for long-term deformation analysis of FRP-C specimens with different geometric and material properties.

2. Based on the exploration of the mechanism underlying long-term sustained load effects on FRP-
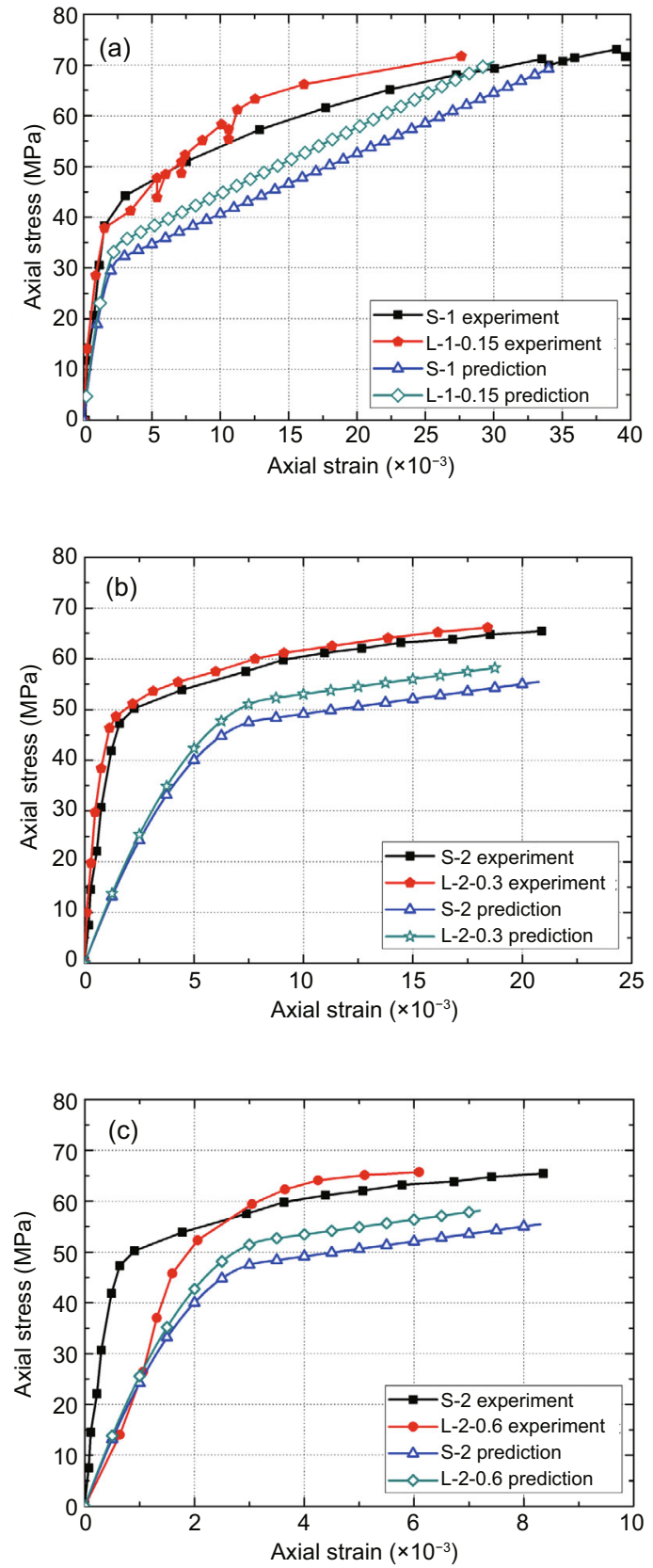

Fig. 7 Comparison of axial stress-strain curves for FRP-C: (a) $r=0.15$; (b) $r=0.30$; (c) $r=0.60$

C, a modified constitutive model of FRP-confined concrete after sustained load was proposed. The effects of sustained axial compression on FRP-C can be summarized as two main parts: (1) the residual hoop strain in FRP due to concrete creep; (2) enhanced plain concrete strength due to sustained load. As the superposition of these two main effects, the change of ultimate strength is determined by their competition, i.e., the ultimate strength of FRP-C 
may either increase or decrease after sustained compression; while ultimate strain can be expected to considerably reduce in most cases. The numerical predictions of the stress-strain curves for FRP-C after sustained load based on the modified constitutive model were generally in good agreement with the experimental results.

Future research needs to focus on different crosssectional FRP-wrapped composite column components, and the studies of concrete-filled FRP tubular columns, which may be expected to be more complicated with potential axial stress redistribution and bi-axial creep in FRP laminates, should be the object of further research.

\section{Acknowledgement}

The authors acknowledge the helpful discussions from Profs. Shao-fan LI (University of California at Berkeley, USA), Bo DIAO (Beihang University, China), and Quanquan GUO (Beihang University, China).

\section{References}

Bazant, Z., 1995. Creep and shrinkage prediction model for analysis and design of concrete structures model B3. Materials and Structures, 28(6):357-365. [doi:10. 1007/BF02473152]

Bazant, Z., Prasannan, S., 1989. Solidification theory for concrete creep, I: formulation. Journal of Engineering Mechanics, 115(8):1691-1703. [doi:10.1061(ASCE)07339399(1989)115.8(1691)]

Berthet, J.F., Ferrier, E., Hamelin, P., 2006. Compressive behavior of concrete externally confined by composite jackets: part B: modeling. Construction and Building Materials, 20(5):338-347. [doi:10.1016/j.conbuildmat. 2005.01.029]

Cook, D.J., Chindaprasirt, P., 1980. Influence of loading history upon the compressive properties of concrete. Magazine of Concrete Research, 32(111):89-100. [doi:10.1680/macr.1980.32.111.89]

Dhir, R.K., Sangha, C.M., 1972. A study of the relationships between time, strength, deformation and fracture of plain concrete. Magazine of Concrete Research, 24:197208.

Findley, W.N., 1960. Mechanism and mechanics of creep of plastics. SPE Journal, 16(1):57-65.

Gopalakrishnan, K.S., Neville, A.M., Ghali, A., 1970. A hypothesis on mechanism creep of concrete with reference to multiaxial compression. ACI Journal Proceedings, 67(1):29-35. [doi:10.14359/7255]

Hellesland, J., Aas-Jakobsen, I.A., Green, R., 1972. A stress and time dependent strength law for concrete. Cement and Concrete Research, 2(3):261-275. [doi:10.1016/0008-8846(72)90069-5]

Hughes, B.P., Ash, J.E., 1970. Some factors influencing the long term strength of concrete. Matériaux et Construction, 3(2):81-84. [doi:10.1007/BF02476261]
Jordaan, I.J., Illston, J.M., 1971. Time-dependent strains in sealed concrete under systems of variable multiaxial stress. Magazine of Concrete Research, 23(75-76):7988.

Lam, L., Teng, J.G., 2003. Design-oriented stress-strain model for FRP-confined concrete. Construction and Building Materials, 17(6-7):471-489. [doi:10.1016/S09500618(03)00045-X]

Lim, J., Ozbakkaloglu, T., 2014. Confinement model for FRP-confined high-strength concrete. Journal of Composites for Construction, 18(4):04013058. [doi:10. 1061/(ASCE)CC.1943-5614.0000376]

Liu, H., He, M.H., Luan, Y.Q., et al., 2013. A modified constitutive model for FRP confined concrete in circular sections and its implementation with OpenSees programming. Journal of Zhejiang University-SCIENCE A (Applied Physics \& Engineering), 14(12):856-866. [doi:10.1631/jzus.A1300185]

Mayfield, B., 1983. Creep and shrinkage in concrete structures. Earthquake Engineering \& Structural Dynamics, 11(4):591-592. [doi:10.1002/eqe.4290110413]

Naguib, W., 2001. Long-term Behavior of Hybrid FRPconcrete Beam-columns. PhD Thesis, University of Cincinnati, Ohio, USA .

Naguib, W., Mirmiran, A., 2003. Creep analysis of axially loaded fiber reinforced polymer-confined concrete columns. Journal of Engineering Mechanics, 129(11): 1308-1319. [doi:10.1061/(ASCE)0733-9399(2003)129:11 (1308)]

Ozbakkaloglu, T., Akin, E., 2012. Behavior of FRP-confined normal- and high-strength concrete under cyclic axial compression. Journal of Composites for Construction, 16(4):451-463. [doi:10.1061/(ASCE)CC.1943$5614.0000273]$

Rousakis, T.C., Karabinis, A.I., Kiousis, P.D., 2007. FRPconfined concrete members: axial compression experiments and plasticity modelling. Engineering Structures, 29(7):1343-1353.

Samaan, M., Mirmiran, A., Shahawy, M., 1998. Model of concrete confined by fiber composites. Journal of Structural Engineering, 124(9):1025-1031. [doi:10.1061/(ASCE)0733-9445(1998)124:9(1025)]

Toutanji, H.A., 1999. Stress-strain characteristics of concrete columns externally confined with advanced fiber composite sheets. ACI Materials Journal, 96(3):397-404.

Wang, Y., Wu, H., 2011. Size effect of concrete short columns confined with aramid FRP jackets. Journal of Composites for Construction, 15(4):535-544. [doi:10. 1061/(ASCE)CC.1943-5614.0000178]

Wang, Y.F., Ma, Y.S., Zhou, L., 2011. Creep of FRPwrapped concrete columns with or without fly ash under axial load. Construction and Building Materials, 25(4):697-704. [doi:10.1061/(ASCE)CC.19435614.0000178

Xiao, Y., Wu, H., 2000. Compressive behavior of concrete confined by carbon fiber composite jackets. Journal of Materials in Civil Engineering, 12(2):139-146. [doi:10.1061/(ASCE)0899-1561(2000)12:2(139)]

Yu, Q., Han, L.H., Zhang, Z., 2003. Long-term effect in FRP-confined concrete stub columns under sustained loading. China Journal of Highway and Transport, 16(3):58-63 (in Chinese). 


\section{中文概要}

\section{题 目: 圆形纤维增强塑料缠绕混凝土柱在持续轴向压缩 下的面向设计的模型分析}

目 的：在实际工程服役过程中, 纤维增强塑料（FRP） 约束混凝土柱在遭遇极限荷载前往往已经经历 了长时间的轴压荷载作用。因此, 相比其短期力 学性能, 本文旨在研究 FPR 约束混凝土柱在长期 荷载作用后的力学性能。

创新点：1. 考虑长期轴压荷载作用, 提出一种轴压作用下 圆形截面 FRP 约束混凝土柱的长期变形分析模 型; 2. 提出了长期轴压作用后的 FRP 约束混凝土
本构模型, 从本构关系的角度描述两个方面的影 响机理。

方 法: 运用混凝土和 FRP 徐变的长期变形分析迭代计算 方法 (图 3)。

结 论: 1. 提出的长期变形分析模型实现了对 FRP 约束混 凝土柱任意目标时刻的应力和应变状态的高效、 准确预测; 2. 将提出的本构模型嵌入有限元软件 中，有效地实现对长期轴压作用的考虑； 3 . 基于 OpenSees 有限元软件, 验证了长期变形分析模型 和本构模型的有效性和准确性。

关键词: FRP 约束混凝土柱; 长期荷载; 长期变形; 徐变; 本构模型 